\title{
Effect and Complications of Everolimus Use for Giant Cardiac Rhabdomyomas with Neonatal Tuberous Sclerosis
}

\author{
Yuka Shibata, $\mathrm{MD}^{1}$ Hidehiko Maruyama, MD, $\mathrm{PhD}^{1}$ Taiyu Hayashi, MD ${ }^{2}$ Hiroshi Ono, $\mathrm{MD}^{2}$ \\ Yuka Wada, MD, PhD ${ }^{1}$ Hideshi Fujinaga, MD, PhD ${ }^{1}$ Shuhei Fujino, MD ${ }^{1}$ Junko Nagasawa, MD ${ }^{1}$ \\ Shoichiro Amari, MD ${ }^{1}$ Keiko Tsukamoto, MD ${ }^{1}$ Yushi Ito, MD ${ }^{1}$
}

\author{
${ }^{1}$ Division of Neonatology, Center for Maternal-Fetal, Neonatal and \\ Reproductive Medicine, Setagaya, Tokyo, Japan \\ 2 Division of Cardiology, National Center for Child Health and \\ Development, Setagaya, Tokyo, Japan
}

Am J Perinatol Rep 2019;9:e213-e217.
Address for correspondence Hidehiko Maruyama, MD, PhD, Division of Neonatology, Center for Maternal-Fetal, Neonatal and Reproductive Medicine, National Center for Child Health and Development, 2-10-1 Okura, Setagaya, Tokyo, Japan (e-mail: maruyama-h@ncchd.go.jp).

\begin{abstract}
Keywords

- complication

- everolimus

- rhabdomyoma

- tuberous sclerosis

Most cardiac rhabdomyomas with tuberous sclerosis (TS) are asymptomatic and spontaneously regress. However, some cases require surgical intervention due to arrhythmia and severe obstruction of cardiac inflow or outflow. We report herein a neonatal case of giant cardiac rhabdomyomas with TS and insufficient pulmonary blood flow from the right ventricle. Lipoprostaglandin E1 was necessary to maintain patency of the ductus arteriosus. We used everolimus, a mammalian target of rapamycin inhibitor, to diminish the cardiac rhabdomyomas. After treatment, the rhabdomyomas shrank rapidly, but the serum concentration of everolimus increased sharply (maximum serum trough level: $76.1 \mathrm{ng} /$ $\mathrm{mL}$ ) and induced complications including pulmonary hemorrhage, liver dysfunction, and acne. After the everolimus level decreased, the complications resolved. Everolimus may be a viable treatment option for rhabdomyomas, but its concentration requires close monitoring to circumvent complications associated with its use.
\end{abstract}

Tuberous sclerosis (TS) is caused by loss-of-function mutations of the TSC1 or TSC2 gene. ${ }^{1}$ TSC1 and TSC2, respectively, encode hamartin and tuberin, which combine to suppress the mammalian target of rapamycin (mTOR) signaling pathway. ${ }^{2,3}$ The mTOR signaling pathway regulates cell proliferation and vascularization. ${ }^{4}$ In patients with TS, the mTOR signaling pathway is abnormally activated due to diminished hamartin or tuberin function, leading to hamartomatous cell growth and other symptoms. ${ }^{2,3}$ Cardiac rhabdomyoma is one of the features of TS in the neonatal and early infantile periods. In half of rhabdomyoma cases, the rhabdomyomas spontaneously regress in childhood. ${ }^{5}$

Everolimus is an mTOR inhibitor. Its effectiveness against subependymal giant cell astrocytomas, ${ }^{3,6}$ renal angiomyolipomas, ${ }^{7}$ and epilepsy ${ }^{8}$ in patients with TS has been documented.

received

November 8, 2018

accepted

March 5, 2019
DOI https://doi.org/

10.1055/s-0039-1692198. ISSN 2157-6998.
There are some reports of cardiac rhabdomyoma treatment using everolimus, ${ }^{9-17}$ but none describes the serious complications associated with its use. We report herein a neonate with TS and giant cardiac rhabdomyomas occupying the right ventricular cavity, impeding ventricular function, and decreasing pulmonary blood flow. Lipoprostaglandin E1 (lipo-PGE1) was required to maintain patency of the ductus arteriosus. Everolimus administration successfully reduced the tumor size although the clinical course was complicated by a pulmonary hemorrhage attributed to the adverse effects of everolimus.

\section{Case Report}

A 43-year-old woman was referred for fetal echocardiography at 21 gestational weeks due to multiple intracardiac

Copyright $\odot 2019$ by Thieme Medical Publishers, Inc., 333 Seventh Avenue, New York, NY 10001, USA. Tel: +1(212) 584-4662.
License terms

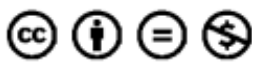


tumors. Although the fetus had cardiac enlargement with a cardiac thoracic area ratio of $67 \%$ at 35 gestational weeks, the fetus developed neither arrhythmia nor hydrops.

A male infant was born at 38 weeks' gestation by scheduled cesarean section due to a previous cesarean section. The birth weight was $2,029 \mathrm{~g}$, the heart rate was 138 beats per minute, the respiratory rate was 20 breaths per minute, the blood pressure was $60 / 37 \mathrm{~mm} \mathrm{Hg}$, and oxygen saturation was $90 \%$ without any respiratory support at neonatal intensive care unit admission. A systolic heart murmur (grade 4/6) and peripheral coldness were found. There was no skin lesion, and the blood test showed no abnormalities.

The largest intracardiac tumor, $35 \mathrm{~mm} \times 21 \mathrm{~mm}$ in size,

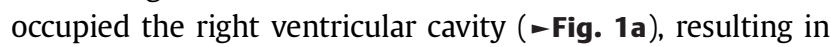
decreased right ventricular output. Echocardiography showed scant antegrade blood flow via the pulmonary valve and significant pulmonary regurgitation caused by backward blood flow from the ductus arteriosus. The right atrium was dilated, and a right-to-left shunt through the foramen ovale was detected. Stenosis of the left ventricular outflow tract due to the tumor was observed, and the flow velocity of the ascending aorta increased $(1.5 \mathrm{~m} / \mathrm{s})$, but the systemic blood pressure remained normal. Since the pulmonary blood flow was dependent on the ductus arteriosus, we started lipo-PGE1 (5 ng/kg/min) soon after birth to maintain patency of the ductus arteriosus.

A magnetic resonance imaging of the brain showed cerebral white matter radial migration lines, a cortical tuber, and a subependymal nodule. Multiple retinal nodular hamartomas were also observed. TS was diagnosed based on these three major findings (brain, retina, and heart). ${ }^{1}$

Volume reduction of the cardiac rhabdomyomas was crucial to maintain pulmonary blood flow. We decided to use everolimus to reduce the cardiac rhabdomyomas rapidly. We started once daily oral everolimus administration on day 4. The initial dosage of $0.4 \mathrm{mg} / \mathrm{d}\left(2.8 \mathrm{mg} / \mathrm{m}^{2} / \mathrm{d}, 0.2 \mathrm{mg} / \mathrm{kg} / \mathrm{d}\right)$ was decided based on previous reports. ${ }^{3,18}$ The target trough level was set at 5 to $15 \mathrm{ng} / \mathrm{mL}^{6}{ }^{6}$ Echocardiography at day 7 demonstrated a decrease in the tumor size in the right ventricle and an increase in the antegrade blood flow via the pulmonary valve. We terminated lipo-PGE1.
We experienced a serious complication at day 6, 3 days after the initiation of everolimus administration, when the patient's respiratory condition worsened and mechanical ventilation was started. Continuous bloody tracheal aspiration indicated a pulmonary hemorrhage, and the laboratory data revealed severe coagulopathy with a prothrombin time-international normalized ratio (PT-INR) of 2.4 and fibrinogen value of $52 \mathrm{mg} / \mathrm{dL}$, as well as elevated liver enzymes. We decided to stop everolimus on day 7 after the fourth administration. After a single infusion of freshfrozen plasma, the coagulopathy improved (PT-INR 1.6 and fibrinogen $158 \mathrm{mg} / \mathrm{dL}$ ) at day 9 . Acne, which appeared on the bilateral cheeks at day 8 , was treated with topical quinolone medication and improved after 2 weeks. Hyperlipidemia, hyperglycemia, and stomatitis were not observed.

Echocardiography at day 16 showed closure of the ductus arteriosus, confirming that biventricular circulation was achieved. The patient was weaned from mechanical ventilation on the same day.

With general improvement in the patient's condition, we tried to restart everolimus in the hope of further reducing the tumor size. At day 10, everolimus was administered at a lower dose of $0.1 \mathrm{mg} / \mathrm{d}$. However, we discontinued everolimus again after we obtained the serum drug concentration measurement for day 7 showing a trough level of 76.1 $\mathrm{ng} / \mathrm{mL}$, which significantly exceeded the target level. At day 25 , everolimus was administered at a dose of $0.025 \mathrm{mg} / \mathrm{d}$, which resulted in a re-elevation of the liver enzymes. After everolimus was terminated altogether, the liver enzyme levels normalized again. Changes in the serum everolimus concentration and liver enzymes are shown in - Fig. 2 .

Echocardiography at days 20 (-Fig. 1b) and 42 (-Fig. 1c) showed regression of the giant tumor in the right ventricle. The patient was discharged at day 54 .

\section{Discussion}

Everolimus was effective as a treatment of the giant cardiac rhabdomyomas with TS in our case; the drug reduced the tumor size rapidly, increased pulmonary blood flow, and
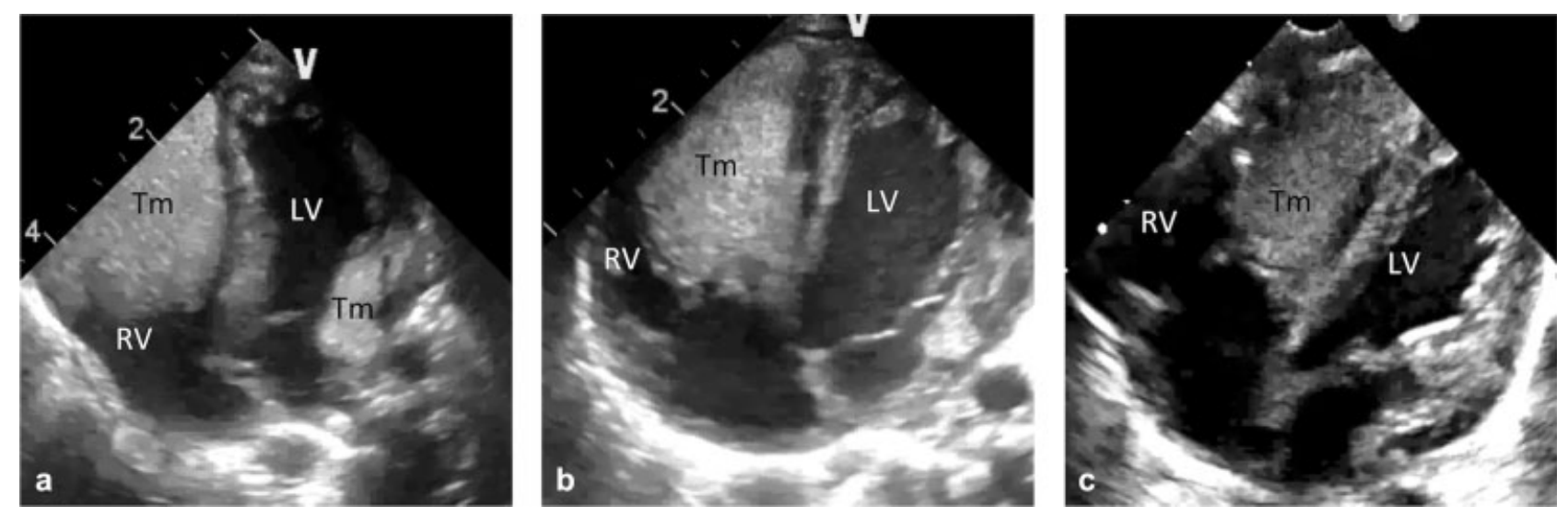

Fig. 1 Figures show view of four chambers on echocardiography. (a) The patient at birth. Multiple tumors were found in both ventricles. The largest rhabdomyoma occupied most of the right ventricular cavity (size: $35 \times 21 \mathrm{~mm}$ ). (b) The patient at day 20 . The largest rhabdomyoma showed regression (size: $28 \times 15 \mathrm{~mm}$ ). (c) The patient at day 42 . The largest rhabdomyoma significantly regressed (size $24 \times 11 \mathrm{~mm}$ ). LV, left ventricle; RV, right ventricle; Tm, tumor. 


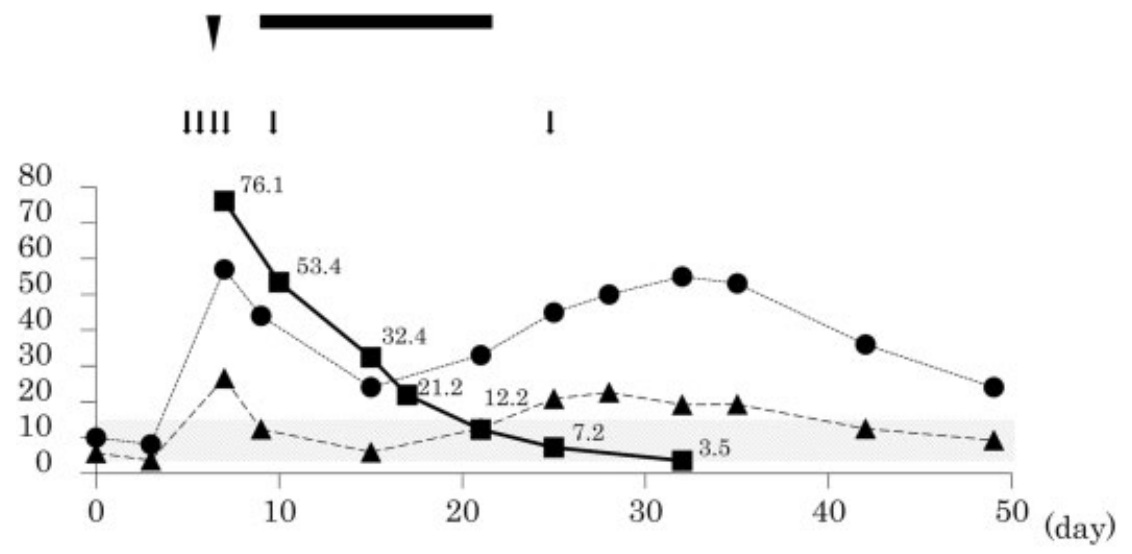

Fig. 2 Figure shows the administration and the serum concentration of everolimus, serum AST and ALT levels, and major complications. Squares indicate the trend in the everolimus trough level $(\mathrm{ng} / \mathrm{mL})$. The numbers next to the squares indicate the everolimus trough level. Shaded areas indicate the target everolimus trough level $(5-15 \mathrm{ng} / \mathrm{mL})$. Triangles and circles indicate the trend in AST/10 (U/L) and ALT (U/L), respectively. Arrows indicate the day of everolimus administration, and the arrowhead indicates the day on which pulmonary hemorrhage occurred. Square bar indicates the duration of acne. The high serum trough level of everolimus may be related to the pulmonary hemorrhage, acne, and liver dysfunction seen in this patient.

rendered surgical intervention unnecessary. Several reports have demonstrated the effectiveness of this drug (-Table 1)..$^{9-17}$ Cardiac rhabdomyomas with TS usually spontaneously regress in childhood. ${ }^{5}$ Therapeutic intervention is not needed unless arrhythmia or severe intracardiac obstruction occurs. ${ }^{19}$ In cases of refractory arrhythmia or severe obstruction of blood flow, surgery for tumor resection or single ventricular hemodynamics is necessary during the neonatal period. ${ }^{20}$ Given the effectiveness of everolimus in rapidly reducing the size of rhabdomyomas, the drug may be a viable treatment option for giant cardiac rhabdomyomas in patients with TS.

The appropriate dosage of everolimus has not been determined. Previous studies have set the everolimus target trough level at 5 to $15 \mathrm{ng} / \mathrm{mL} .^{9,10,12-17}$ The package insert recommends monitoring the serum drug concentration from 2 weeks after commencing administration or changing the dosage. In our case, everolimus was administered at a dose of $0.2 \mathrm{mg} / \mathrm{kg}$ once daily starting at day 4 . The serum everolimus concentration, measured immediately before the administration of the 4 th dose at day 7 , was $76.1 \mathrm{ng} / \mathrm{mL}$, which was much higher than the target trough level. Our measurement of the serum drug concentration, which we made much earlier than recommended by the package insert, indicated that the initial dose should have been lower. Although the half-life of the drug is reportedly 25 to 43 hours, ${ }^{21}$ the estimated half-life in our case was 84 to 128 hours, far exceeding the reported values. Our case underscores the fact that meticulous monitoring of the serum everolimus concentration is essential.

Our patient developed pulmonary hemorrhage coinciding with the elevation of the serum everolimus concentration. Everolimus reportedly damages not only tumor vessels but also normal blood vessels ${ }^{22}$ and can lead to pulmonary hemorrhage. ${ }^{23} \mathrm{~A}$ recent in vivo study suggested that $\mathrm{mTOR}$ inhibitors may interact with the STAT1 gene, causing amplification of cellular apoptosis and augmenting lung injury. ${ }^{24}$ Coagulopathy, which developed in our patient, is another possible complica- tions. In the present case, in addition to increased pulmonary blood flow due to lipo-PGE1, tumor shrinkage caused by everolimus increased the pulmonary blood flow. All these factors contributed to the pulmonary hemorrhage.

Everolimus can adversely affect liver function and lead to decreased metabolism of the drug. In our patient, an elevation of aspartate transaminase and alanine transaminase was evident at day 7 when the serum everolimus concentration peaked, and acne was also observed. As summarized in - Table 1, complications reported in neonates include mouth ulcers, hyperlipidemia, etc. Liver dysfunction and acne were listed among the possible complications in the package insert in 2018, in which the incidence rates of liver dysfunction and acne were 1 to $10 \%$. Half the Japanese population lack the activity of CYP3A5, the enzyme involved in everolimus metabolism. ${ }^{21,25}$ Although we did not assess enzyme activity in our patient, the extremely high concentration of everolimus and the prolongation of its half-life might be related to the lack of CYP3A5 activity.

The toxic and therapeutic levels of the serum everolimus concentration also require clarification. Complications, such as mouth ulcer and hyperlipidemia, have been documented in patients with concentrations of everolimus below the target trough level of 5 to $15 \mathrm{ng} / \mathrm{mL} .^{9,11,15}$ In contrast, there were no complications in a case reported by Shigemitsu et $\mathrm{al}^{13}$ despite a maximum trough level of $21 \mathrm{ng} / \mathrm{mL}$.

Follow-up after the cessation of everolimus treatment is also important. Some studies reported tumor regrowth after stopping everolimus administration. ${ }^{11,12}$ It is also necessary to follow the long-term growth and development of pediatric patients who have received everolimus. There are as yet no reports on the long-term prognosis of neonates or young children who have received this treatment. ${ }^{26}$

In conclusion, everolimus may be a viable treatment option for giant cardiac rhabdomyomas in patients with TS. When administering the drug to neonates, the patient should be closely observed for possible side effects, and the serum drug level should be routinely monitored. 


\begin{tabular}{|c|c|c|c|c|c|c|c|c|c|c|}
\hline 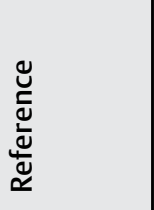 & 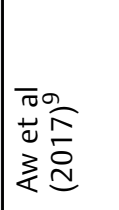 & 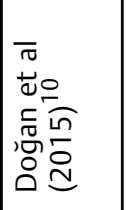 & 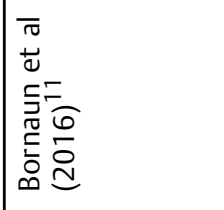 & 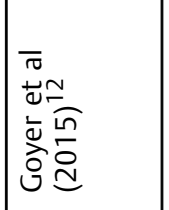 & 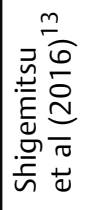 & 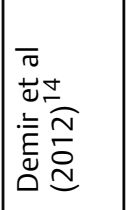 & 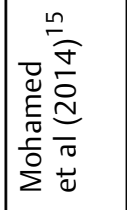 & 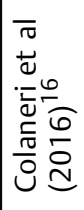 & 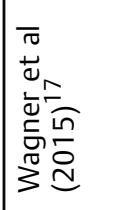 & $\begin{array}{l}0 \\
\tilde{y} \\
\vdots \\
0\end{array}$ \\
\hline 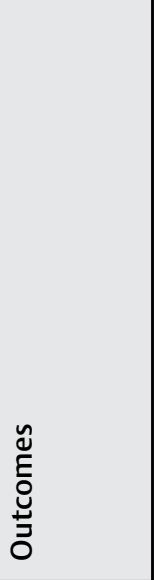 & 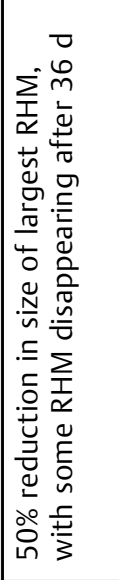 & 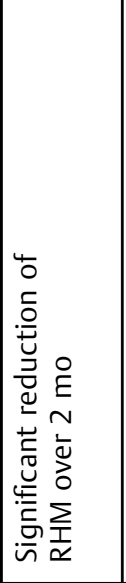 & 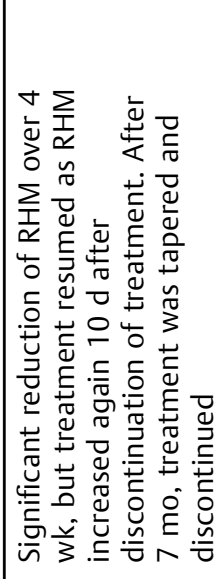 & 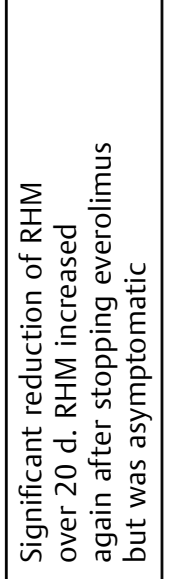 & 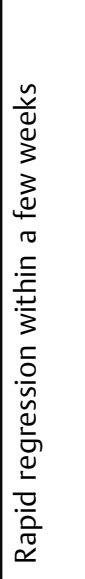 & 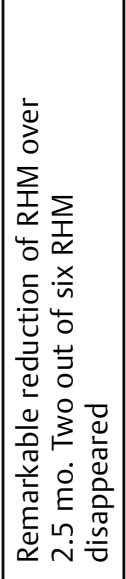 & 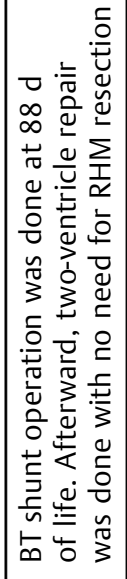 & 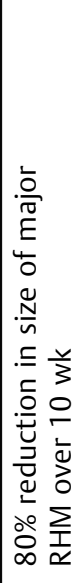 & 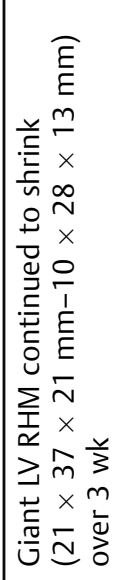 & 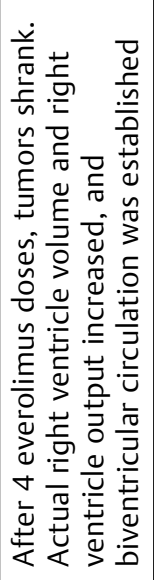 \\
\hline 蒿 & 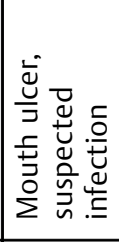 & 文 & 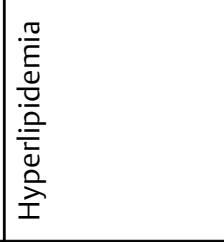 & $\mid \begin{array}{l}0 \\
\tilde{\Xi} \\
z\end{array}$ & $\begin{array}{l}0 \\
\tilde{0} \\
z\end{array}$ & 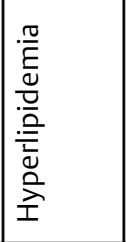 & 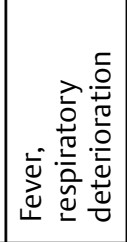 & 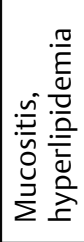 & 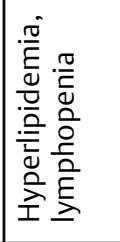 & 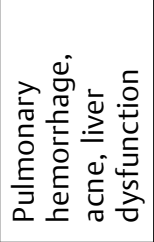 \\
\hline 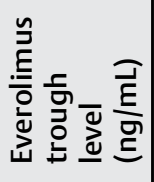 & $\stackrel{-}{2}$ & $\stackrel{\infty}{\sim}$ & $\stackrel{0}{\sim}$ & $\mp$ & $\bar{N}$ & $\stackrel{\text { ñ }}{\infty}$ & $\hat{\stackrel{m}{m}}$ & $\stackrel{0}{-}$ & $\stackrel{\infty}{\circ}$ & $\bar{\varphi}$ \\
\hline 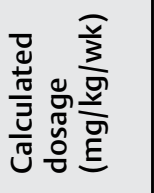 & $\bar{N}$ & $\stackrel{\substack{n \\
\hdashline}}{0}$ & શิ & $\stackrel{\sim}{0}$ & $\stackrel{\infty}{\stackrel{\infty}{0}}$ & भ̂n. & î. & $\begin{array}{l}\infty \\
\infty \\
0 \\
0\end{array}$ & $\stackrel{\text { ọ }}{r}$ & $\stackrel{\infty}{m}$ \\
\hline פ & $\begin{array}{l}\frac{\partial}{\sigma} \\
\frac{\pi}{\sigma} \\
\overline{0}\end{array}$ & 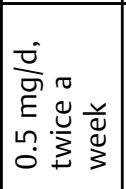 & 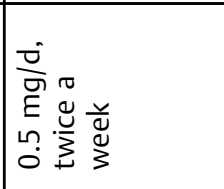 & $\mid \begin{array}{c}\frac{\sigma}{\sigma} \\
\frac{E}{\sigma} \\
\frac{\sigma}{0}\end{array}$ & 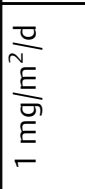 & 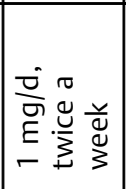 & $\mid \begin{array}{l}\frac{\sigma}{\sigma} \\
\frac{E}{\sigma} \\
\overline{0}\end{array}$ & 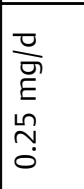 & 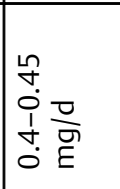 & 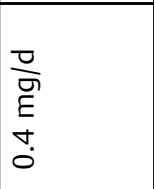 \\
\hline 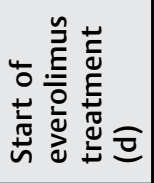 & - & $\sim$ & $\wedge$ & $\nabla$ & $\stackrel{\curvearrowleft}{\ulcorner}$ & 0 & 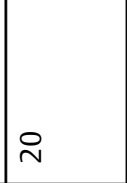 & $\frac{\text { 并 }}{-}$ & $\sim$ & $\nabla$ \\
\hline 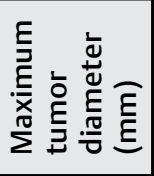 & $\infty$ & $\stackrel{\Xi}{\sim}$ & શ & $\stackrel{\sim}{\stackrel{N}{N}}$ & $\stackrel{\varphi}{m}$ & $\stackrel{\Perp}{\sim}$ & $\stackrel{0}{\circ}$ & 우 & $\hat{m}$ & $\stackrel{\llcorner}{m}$ \\
\hline ত্ & 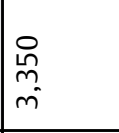 & $\begin{array}{l}\text { 员 } \\
\text { hn } \\
\text { m. }\end{array}$ & $\begin{array}{l}8 \\
\text { in } \\
\text { m. }\end{array}$ & $\begin{array}{l}0 \\
6 \\
- \\
-\end{array}$ & 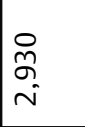 & 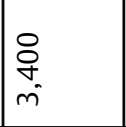 & $\stackrel{\circ}{\circ}$ & $\begin{array}{l}8 \\
0 \\
i\end{array}$ & 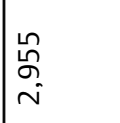 & $\begin{array}{l}\stackrel{\text { I }}{0} \\
\text { O } \\
\text { i }\end{array}$ \\
\hline$\frac{\widehat{n}}{\frac{N}{3}}$ & $\stackrel{\infty}{m}$ & 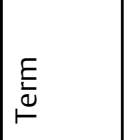 & $\stackrel{\infty}{m}$ & $\stackrel{p}{m}$ & $\hat{m}$ & 窇 & 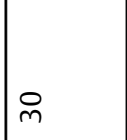 & $\stackrel{\stackrel{n}{m}}{m}$ & $\underset{\stackrel{E}{E}}{E}$ & $\stackrel{\infty}{m}$ \\
\hline $\begin{array}{l}\tilde{\Xi} \\
\text { 心̃ }\end{array}$ & - & $\sim$ & $m$ & $\nabla$ & Ln & 6 & $\wedge$ & $\infty$ & $a$ & $\stackrel{\circ}{-}$ \\
\hline
\end{tabular}




\section{Ethical Approval}

All the procedures involving human participants were performed in accordance with the ethical standards of the institution and with the 1964 Helsinki declaration and its later amendments. The approval of the ethics review committee and parental consent to use everolimus were obtained. Parental written informed consent was obtained for this report.

\section{Funding}

No financial assistance was received to support this study.

\section{Conflict of Interest}

All the authors declare that they have no conflict of interest.

\section{Acknowledgment}

We thank Mr. James R. Valera for his assistance with editing this article.

\section{References}

1 Northrup H, Krueger DA; International Tuberous Sclerosis Complex Consensus Group. Tuberous sclerosis complex diagnostic criteria update: recommendations of the 2012 International Tuberous Sclerosis Complex Consensus Conference. Pediatr Neurol 2013;49(04):243-254

2 Chan JA, Zhang H, Roberts PS, et al. Pathogenesis of tuberous sclerosis subependymal giant cell astrocytomas: biallelic inactivation of TSC1 or TSC2 leads to mTOR activation. J Neuropathol Exp Neurol 2004;63(12):1236-1242

3 Krueger DA, Care MM, Holland K, et al. Everolimus for subependymal giant-cell astrocytomas in tuberous sclerosis. N Engl J Med 2010;363(19):1801-1811

4 Potter CJ, Huang H, Xu T. Drosophila Tsc1 functions with Tsc2 to antagonize insulin signaling in regulating cell growth, cell proliferation, and organ size. Cell 2001;105(03):357-368

5 Smythe JF, Dyck JD, Smallhorn JF, Freedom RM. Natural history of cardiac rhabdomyoma in infancy and childhood. Am J Cardiol 1990;66(17):1247-1249

6 Franz DN, Belousova E, Sparagana S, et al. Efficacy and safety of everolimus for subependymal giant cell astrocytomas associated with tuberous sclerosis complex (EXIST-1): a multicentre, randomised, placebo-controlled phase 3 trial. Lancet 2013;381 (9861):125-132

7 Bissler JJ, Kingswood JC, Radzikowska E, et al. Everolimus for angiomyolipoma associated with tuberous sclerosis complex or sporadic lymphangioleiomyomatosis (EXIST-2): a multicentre, randomised, double-blind, placebo-controlled trial. Lancet 2013;381(9869):817-824

8 Krueger DA, Wilfong AA, Holland-Bouley K, et al. Everolimus treatment of refractory epilepsy in tuberous sclerosis complex. Ann Neurol 2013;74(05):679-687

9 Aw F, Goyer I, Raboisson MJ, Boutin C, Major P, Dahdah N. Accelerated cardiac rhabdomyoma regression with everolimus in infants with tuberous sclerosis complex. Pediatr Cardiol 2017; 38(02):394-400
10 Doğan V, Yeşil Ş, Kayalı Ş, et al. Regression of symptomatic multiple cardiac rhabdomyomas associated with tuberous sclerosis complex in a newborn receiving everolimus. J Trop Pediatr 2015;61(01):74-77

11 Bornaun H, Öztarhan K, Erener-Ercan T, et al. Regression of cardiac rhabdomyomas in a neonate after everolimus treatment. Case Rep Pediatr 2016;2016:8712962

12 Goyer I, Dahdah N, Major P. Use of mTOR inhibitor everolimus in three neonates for treatment of tumors associated with tuberous sclerosis complex. Pediatr Neurol 2015;52(04):450-453

13 Shigemitsu Y, Baba K, Kondo M, et al. Regression of massive cardiac rhabdomyoma causing circulatory collapse with everolimus therapy. Pediatr Cardiol Cardiac Surg 2016;32:439-444

14 Demir HA, Ekici F, Yazal Erdem A, Emir S, Tunç B. Everolimus: a challenging drug in the treatment of multifocal inoperable cardiac rhabdomyoma. Pediatrics 2012;130(01):e243-e247

15 Mohamed I, Ethier G, Goyer I, Major P, Dahdah N. Oral everolimus treatment in a preterm infant with multifocal inoperable cardiac rhabdomyoma associated with tuberous sclerosis complex and a structural heart defect. BMJ Case Rep 2014;2014:pii: bcr2014205138

16 Colaneri M, Quarti A, Pozzi M. Everolimus-induced near-resolution of giant cardiac rhabdomyomas and large renal angiomyolipoma in a newborn with tuberous sclerosis complex. Cardiol Young 2016;26(05):1025-1028

17 Wagner R, Riede FT, Seki H, et al. Oral everolimus for treatment of a giant left ventricular rhabdomyoma in a neonate-rapid tumor regression documented by real time 3D echocardiography. Echocardiography 2015;32(12):1876-1879

18 Fujino M, Ehara E, Kuki I, et al. Rapid regression of cardiac rhabdomyoma after everolimus administration in an infant with tuberous sclerosis. Pediatr Cardiol Cardiac Surg 2016; 32:251-256

19 Stiller B, Hetzer R, Meyer R, et al. Primary cardiac tumours: when is surgery necessary? Eur J Cardiothorac Surg 2001;20(05): 1002-1006

20 Bielefeld KJ, Moller JH. Cardiac tumors in infants and children: study of 120 operated patients. Pediatr Cardiol 2013;34(01): 125-128

21 Masuda S. Individualized dosage of everolimus in organ transplant patients by evidence based medicine. Organ Biology 2015; 22:105-110

22 Kubota Y. Tumor angiogenesis and anti-angiogenic therapy. Keio J Med 2012;61(02):47-56

23 Vandewiele B, Vandecasteele SJ, Vanwalleghem L, De Vriese AS. Diffuse alveolar hemorrhage induced by everolimus. Chest 2010; 137(02):456-459

24 Fielhaber JA, Carroll SF, Dydensborg AB, et al. Inhibition of mammalian target of rapamycin augments lipopolysaccharideinduced lung injury and apoptosis. J Immunol 2012;188(09): 4535-4542

25 Uesugi M, Kikuchi M, Shinke H, et al. Impact of cytochrome P450 3A5 polymorphism in graft livers on the frequency of acute cellular rejection in living-donor liver transplantation. Pharmacogenet Genomics 2014;24(07):356-366

26 Kotulska K, Chmielewski D, Borkowska J, et al. Long-term effect of everolimus on epilepsy and growth in children under 3 years of age treated for subependymal giant cell astrocytoma associated with tuberous sclerosis complex. Eur J Paediatr Neurol 2013;17 (05):479-485 